АТЕРОСКЛЕРОЗ ПЕРИФЕРИЧЕСКИХ АРТЕРИЙ И ПОКАЗАТЕЛИ НИЗКОИНТЕНСИВНОГО ВОСПАЛЕНИЯ У ПАЦИЕНТОВ С ИШЕМИЧЕСКОЙ БОЛЕЗНЬЮ СЕРДЦА И САХАРНЫМ ДИАБЕТОМ 2 ТИПА

( ) В.В. Генкель* , К.В. Никушкина, Т.И. Никонова, И.И. Шапошник

ФГБОУ ВО Южно-Уральский государственный медицинский университет Минздрава России, Челябинск

ОБОСНОВАНИЕ. Изучение низкоинтенсивного воспаления у пациентов с сахарным диабетом 2 типа (СД2) и атеросклеротическими сердечно-сосудистыми заболеваниями является актуальной проблемой, так как более глубокое понимание каскада воспалительных реакций, возможно, опосредующих тяжелое атеросклеротическое поражение различных сосудистых бассейнов у пациентов с СД, несет возможность внедрения в практику более совершенных диагностических и терапевтических подходов.

ЦЕЛЬ. Изучить показатели низкоинтенсивного воспаления и атеросклеротическое поражение периферических артерий в их взаимосвязи у пациентов с ишемической болезнью сердца (ИБС) и СД2.

МЕтОДЫ. В исследование были включены 137 пациентов (77 мужчин и 60 женщин) с ИБС (средний возраст $62,0(57,0-66,0)$ лет). В первую группу были включены 67 пациентов с ИБС и СД2, во вторую - 70 с ИБС и без. Субклиническое воспаление оценивали по уровням высокочувствительного С-реактивного белка (вчСРБ), интерлейкинов (ИЛ): ИЛ-1ß, ИЛ-6, ИЛ-8, ИЛ-10 и фактора некроза опухоли альфа (ФНО-а). Всем пациентам проводили дуплексное сканирование сонных артерий и артерий нижних конечностей (АНК).

РЕЗУЛЬТАТЫ. Пациенты с ИБС и СД2 отличались статистически значимо большими значениями стенозирования артерий каротидного бассейна и АНК. Выявлены прямые корреляционные связи между маркерами воспаления и степенью стенозирования бедренных и берцовых артерий, а также толщиной комплекса интима-медиа сонных и бедренных артерий. В группе пациентов с СД2 значения ИЛ-1 $\beta$ составляли 2,04 (0,98-2,52) пг/мл, что было значимо меньше в сравнении с пациентами 2-й группы - 2,43 $(1,84-3,19)$ пг/мл (p=0,010). Значения ИЛ-6 также были статистически значимо ниже в 1-й группе пациентов - 1,84 (0,73-4,41) пг/мл против 3,73 (2,27-10,2) пг/мл в 1-й и 2-й группах соответственно ( $p=0,008)$. Доза метформина обратно коррелировала с уровнем ИЛ-6 $(r=-0,314 ; p=0,003)$.

ЗАКЛЮЧЕНИЕ. Пациенты С ИБС и СД2 в сравнении с пациентами без СД отличались статистически значимо большими значениями стенозирования периферических артерий. Уровни ИЛ-1 $\beta$ и ИЛ-6 в группе пациентов с ИБС и СД2 были статистически значимо ниже в сравнении с пациентами без СД. Доза получаемого метформина обратно коррелировала с уровнем ИЛ-6.

КЛЮЧЕВЫЕ СЛОВА: атеросклероз периферических артерий; сахарный диабет; интерлейкин-6; интерлейкин-1ß; метформин

\title{
PERIPHERAL ARTERIAL DISEASE AND INDICATORS OF LOW-GRADE INFLAMMATION IN PATIENTS WITH CORONARY ARTERY DISEASE AND TYPE 2 DIABETES MELLITUS
}

\author{
(c) Vadim V. Genkel*, Karina V. Nikushkina, Tansilla I. Nikonova, Igor I. Shaposhnik
}

South-Ural State Medical University, Chelyabinsk, Russia

BACKGROUND: The study of low-grade inflammation in patients with type 2 diabetes mellitus (T2DM) and atherosclerotic cardiovascular diseases is a pressing problem. A deeper understanding of the cascade of inflammatory reactions, possibly mediating the severe atherosclerotic lesions of various vascular pools in patients with diabetes, has the potential to introduce more sophisticated diagnostic and therapeutic approaches into practice.

AIM: To study the interrelation of low-grade inflammation and atherosclerosis of peripheral arteries in patients with coronary artery disease (CAD) and T2DM.

MATERIALS AND METHODS: The study included 137 patients (77 men and 60 women) with CAD. The average age of patients was 62.0 (57.0-66.0) years. The first group included 67 patients with CAD and T2DM, and the second group included 70 patients with CAD. Low-grade inflammation was assessed by the levels of high-sensitivity C-reactive protein, interleukin (IL)$1 \beta$, IL-6, IL-8, IL-10 and TNF-a. All patients underwent duplex scanning of carotid arteries and lower extremity arteries (LEAs).

RESULTS: Patients with CAD and T2DM showed significantly greater values of stenosis of carotid arteries and LEAs. Direct correlation was revealed between markers of inflammation and the degree of stenosis of the femoral and tibial arteries, as well as the intima-media thickness of the carotid and femoral arteries. In the group of patients with T2DM, the value of 
IL-1 $\beta$ was $2.04(0.98-2.52) \mathrm{pg} / \mathrm{mL}$, which was significantly less than 2.43 (1.84-3.19) pg/mL for patients in the second group $(p=0.010)$. The values of IL-6 were also significantly lower in the first group of patients, at $1.84(0.73-4.41) \mathrm{pg} / \mathrm{mL} \mathrm{vs} .3 .73$ (2.27-10.2) pg/mL in the first and second groups, respectively $(p=0.008)$. The dose of metformin was inversely correlated with the level of IL-6 $(r=-0.314, p=0.003)$.

CONCLUSIONS: Patients with CAD and T2DM compared with patients without diabetes had significantly greater values of stenosis of peripheral arteries. The levels of IL-1 $\beta$ and IL- 6 in the group of patients with CAD and T2DM were significantly lower in comparison with patients without diabetes. The dose of metformin was inversely correlated with the level of IL-6.

KEYWORDS: peripheral artery disease; diabetes mellitus; interleukin-6; interleukin-1 $\beta$; metformin

Важность воспаления в инициации и прогрессировании атеросклероза рассматривается в рамках воспалительной гипотезы атерогенеза в течение 20 лет [1]. Значительный вклад активности воспалительного процесса в развитие атеросклероза нашел свое отражение в ряде клинических исследований, доказавших взаимосвязь маркеров воспаления, показателей ремоделирования сердечно-сосудистой системы и тяжести атеросклероза [2, 3]. Установлена ценность маркеров воспаления в качестве предикторов неблагоприятных сердечно-сосудистых событий и прогноза пациентов с атеросклерозом различных сосудистых бассейнов [4-6]. Хроническое субклиническое воспаление (англ. «low-grade inflammation», синонимы: «низкоинтенсивное воспаление», «микровоспаление») является одним из механизмов, реализующих атерогенные эффекты сахарного диабета 2 типа (СД2) [7]. Установлено, что СД2 ассоциируется с провоспалительным иммунным статусом и увеличением уровня циркулирующих маркеров воспаления [8-10]. Провоспалительные цитокины, адипокины связывают висцеральное ожирение, инсулинорезистентность и атеросклероз [11].

В клинических исследованиях изучались взаимосвязи провоспалительных цитокинов и особенностей атеросклеротического поражения сосудистых бассейнов в различных популяциях пациентов. У пациентов с каротидным атеросклерозом установлено увеличение фибриногена, интерлейкина-6 (ИЛ-6) и высокочувствительного С-реактивного белка (вчСРБ) [6]. У пациентов с "нестабильными" атеросклеротическими бляшками (АСБ) в артериях каротидного бассейна в сравнении с пациентами со "стабильными" атеромами отмечается значительное увеличение вчСРБ, фактора некроза опухолей а (ФНО-а), ИЛ-6 [12]. В мета-анализе B. Zhang и соавт.установлены корреляционные взаимосвязи уровня ИЛ-6 и толщины комплекса интима-медиа (ТКИМ) общих сонных артерий (ОСА) [13]. В ряде исследований установлены взаимосвязи таких цитокинов, как ИЛ-1, ИЛ-6, ИЛ-8, вчСРБ и различных клинических особенностей артерий нижних конечностей [14]. Известна прогностическая ценность ИЛ-6 в отношении снижения лодыжечно-плечевого индекса (ЛПИ) в течение 5 и 12 лет наблюдения, а также ИЛ-6 и вчСРБ - в отношении снижения функционального статуса пациентов [15].

Важность изучения состояния низкоинтенсивного воспаления у пациентов с СД2 и атеросклеротическими сердечно-сосудистыми заболеваниями не подлежит сомнению, так как более глубокое понимание каскада воспалительных реакций, возможно, опосредующих более тяжелое атеросклеротическое поражение различных сосудистых бассейнов у пациентов с СД2 в сравнении с пациентами с нормальным углеводным обменом, несет возможность внедрения в клиническую практику более совершенных диагностических подходов, а также превентивных и терапевтических стратегий. Вместе с тем имеются лишь ограниченные данные по указанной тематике, особенно в специфических популяциях пациентов в условиях реальной клинической практики на фоне современной многокомпонентной терапии.

\section{ЦЕЛЬ}

Изучить показатели низкоинтенсивного воспаления и атеросклеротического поражения периферических артерий в их взаимосвязи у пациентов с ишемической болезнью сердца (ИБС) и СД2.

\section{МЕТОДЫ}

\section{Дизайн исследования}

Дизайн исследования - одномоментное поперечное.

\section{Критерии соответствия}

Критерии включения в исследование: стабильная ИБС, подписанное информированное согласие на участие в исследовании. Критерии невключения и/или исключения из исследования: острый период нарушений мозгового или коронарного кровообращения, оперативные вмешательства в предшествующие 3 мес, тяжелые нарушения функции печени и почек (снижение скорости клубочковой фильтрации (СКФ) менее 30 мл/мин/1,73 м²), злокачественные новообразования, психические заболевания, злоупотребление алкоголем и психоактивными веществами.

\section{Условия проведения}

Набор пациентов с установленным диагнозом ИБС проводили на базе терапевтической клиники МАУЗ ОТКЗ ГКБ №1 г. Челябинска (кардиологическое отделение, эндокринологическое отделение, терапевтическое отделение, кардиологический кабинет поликлиники).

Продолжительность исследования

Набор пациентов осуществлялся с января 2017 г. по сентябрь 2017 г.

Описание медицинского вмешательства

Использовали методы общеклинического исследования: сбор жалоб, анамнеза заболевания и жизни, физикальное исследование. В план лабораторного исследования входило определение общего холестерина (XC), холестерина липопротеинов низкой плотности (ХС ЛПНП), холестерина липопротеинов высокой плотности (ХС ЛПВП), триглицеридов (ТГ) (Ольвекс Диагностикум, Россия). Состояние углеводного обмена оценивали 
Таблица 1. Клиническая характеристика пациентов

\begin{tabular}{|c|c|c|c|}
\hline Признак & $\begin{array}{c}\text { Группа I } \\
\text { ИБС+СД }(n=67)\end{array}$ & $\begin{array}{c}\text { Группа II } \\
\text { ИБС }(n=70)\end{array}$ & $\mathbf{p}$ \\
\hline Возраст, лет, Ме (ИИ) & $62,0(56,0-66,0)$ & $62,0(58,0-67,0)$ & 0,547 \\
\hline Мужчины, n (\%) & $40(59,7)$ & $37(52,8)$ & 0,492 \\
\hline ИМТ, кг/М², Ме (ИИ) & $30,1(27,7-32,0)$ & $27,3(24,6-31,6)$ & 0,011 \\
\hline OT, см, Me (ИИ) & $97,5(88,5-108)$ & $94,0(84,0-100)$ & 0,010 \\
\hline Абдоминальное ожирение, n (\%) & $54(80,6)$ & $46(65,7)$ & 0,056 \\
\hline Курение, n (\%) & $24(35,8)$ & $24(34,3)$ & 0,860 \\
\hline Длительность ИБС, лет, Ме (ИИ) & $6,00(3,00-11,0)$ & $3,00(2,00-5,00)$ & 0,001 \\
\hline ПИК, n (\%) & $33(49,2)$ & $24(34,3)$ & 0,085 \\
\hline Реваскуляризация миокарда, n (\%) & $23(34,3)$ & $23(32,8)$ & 0,859 \\
\hline Гипертоническая болезнь, n (\%) & $66(98,5)$ & $66(94,3)$ & 0,681 \\
\hline Длительность гипертонической болезни, лет, Ме (ИИ) & $12,0(5,50-20,0)$ & $6,00(3,00-15,0)$ & 0,008 \\
\hline Фибрилляция предсердий, n (\%) & $12(17,9)$ & $8(11,4)$ & 0,337 \\
\hline ОНМК в анамнезе, n (\%) & $7(10,4)$ & $4(5,71)$ & 0,359 \\
\hline Перемежающаяся хромота, n (\%) & $26(38,8)$ & $14(20,0)$ & 0,023 \\
\hline Реваскуляризация периферических артерий, n (\%) & $5(7,46)$ & $4(5,71)$ & 0,741 \\
\hline Хроническая сердечная недостаточность, n (\%) & $62(92,5)$ & $40(57,1)$ & 0,0001 \\
\hline Дезагреганты, n (\%) & $60(89,5)$ & $54(77,1)$ & 0,068 \\
\hline Ацетилсалициловая кислота, n (\%) & $58(86,5)$ & $49(70,0)$ & 0,023 \\
\hline Клопидогрель, n (\%) & $29(43,3)$ & $29(41,4)$ & 0,864 \\
\hline Пероральные антикоагулянты, n (\%) & $11(16,4)$ & $4(5,71)$ & 0,057 \\
\hline Бета-адреноблокаторы, n (\%) & $50(74,6)$ & $43(61,4)$ & 0,104 \\
\hline Ингибиторы АПФ/БРА, n (\%) & $58(86,5)$ & $54(77,1)$ & 0,187 \\
\hline Блокаторы медленных кальциевых каналов, n (\%) & $15(22,4)$ & $6(8,57)$ & 0,032 \\
\hline Диуретики, n (\%) & $20(29,8)$ & $8(11,4)$ & 0,001 \\
\hline Статины, n (\%) & $54(80,6)$ & $49(70,0)$ & 0,106 \\
\hline
\end{tabular}

Примечания: ИМТ - индекс массы тела; ОТ - объем талии; ПИК - постинфарктный кардиосклероз; ОНМК - острое нарушение мозгового кровообращения; АПФ - ангиотензин-превращающий фермент; БРА - блокаторы рецептора ангиотензина II; Ме - медиана; ИИ интерквартильный интервал

по уровню гликированного гемоглобина. Для оценки функционального состояния почек определяли сывороточный креатинин с последующим расчетом СКФ по формуле CKD-EPI (Ольвекс Диагностикум, Россия). Низкоинтенсивное воспаление оценивали по уровням вчСРБ и цитокинов: определяли уровни циркулирующих ИЛ-1及, ИЛ-6, ИЛ-8, ИЛ-10 и ФНО-а с использованием "сэндвич" варианта методики твердофазного иммуноферментного анализа с применением моно- и поликлональных антител. Использовали наборы реагентов производства ЗАО "Вектор-БЕСТ".

Всем пациентам проводили дуплексное сканирование артерий каротидного бассейна и артерий нижних конечностей (АНК). Осматривали с обеих сторон в продольном и поперечном сечении на всем протяжении следующие сосуды: общие сонные артерии (ОСА) с бифуркацией ОСА, внутренние сонные артерии (BCA), наружные сонные артерии (НСА) из переднего и латерального доступа, общие бедренные артерии (ОБА), поверхностные бедренные артерии (ПБА), коленные артерии (ПкА), тибиоперинеальный ствол (ТБС), передние большеберцо- вые артерии (ПББА), задние большеберцовые артерии (ЗББА), артерии тыла стопы. ТКИМ ОСА определяли в автоматическом режиме (функция AutolMT) с обеих сторон в дистальной трети ОСА на 1 см проксимальнее бифуркации ОСА из переднего доступа. Среднюю ТКИМ ОСА (ТКИМср) определяли по формуле:

ТКИМср $=($ ТКИМ ОСАслева + ТКИМ ОСАсправа $) / 2$.

ТКИМ ОБА измеряли в ручном режиме по дальней стенке сосуда на 1 см проксимальнее бифуркации ОБА, размещая метку на границе интимы с анэхогенным просветом артерии и на границе адвентиции с гипоэхогенной средней оболочкой. Подобным образом измеряли ТКИМ ППБА на 1 см дистальнее устья ПБА в продольном режиме. Процент стенозирования измеряли планиметрически в В-режиме по диаметру в поперечном сечении сосуда. Процент стеноза определяли непосредственно в месте локализации АСБ, что соответствовало методу ECST (The European Carotid Surgery Trial). В случае выявления АСБ, стенозирующих просвет сосудов, рассчитывали суммарное значение стенозирования сонных артерий (СуммСтСА), представляющее собой сумму процентов 
Таблица 2. Данные ультразвукового исследования периферических артерий

\begin{tabular}{|c|c|c|c|}
\hline Признак & $\begin{array}{c}\text { Группа I } \\
\text { ИБС+СД }(n=67)\end{array}$ & $\begin{array}{c}\text { Группа II } \\
\text { ИБС }(n=70)\end{array}$ & $\mathbf{p}$ \\
\hline ТКИМср ОСА, мм, Ме (ИИ) & $0,93(0,81-1,04)$ & $0,89(0,77-1,00)$ & 0,177 \\
\hline АСБ в ОСА, n (\%) & $62(92,5)$ & $50(71,4)$ & 0,002 \\
\hline МаксСтСА, \%, Ме (ИИ) & $40,0(32,0-50,0)$ & $30,0(0,00-40,2)$ & 0,0001 \\
\hline СуммСтСА, \%, Me (ИИ) & $96,0(45,0-156)$ & $49,0(0,00-92,5)$ & 0,0001 \\
\hline ТКИМ ЛОБА, мм, Ме (ИИ) & $1,00(0,86-1,20)$ & $0,98(0,78-1,14)$ & 0,129 \\
\hline ТКИМ ПОБА, мм, Ме (ИИ) & $1,00(0,86-1,20)$ & $0,94(0,74-1,13)$ & 0,040 \\
\hline ТКИМср ОБА, мм, Ме (ИИ) & $1,04(0,88-1,17)$ & $0,95(0,77-1,10)$ & 0,057 \\
\hline ТКИМ ЛПБА, мм, Ме (ИИ) & $0,70(0,56-1,00)$ & $0,65(0,54-0,78)$ & 0,017 \\
\hline ТКИМ ППБА, мм, Ме (ИИ) & $0,78(0,62-0,95)$ & $0,63(0,51-0,80)$ & 0,001 \\
\hline ТКИМср ПБА, мм, Ме (ИИ) & $0,77(0,62-0,95)$ & $0,64(0,55-0,76)$ & 0,002 \\
\hline АСБ в АНК, n (\%) & $49(73,1)$ & $46(65,7)$ & 0,361 \\
\hline Стеноз ЛОБА, \%, Ме (ИИ) & $30,0(0,00-45,0)$ & $0,00(0,00-34,2)$ & 0,003 \\
\hline Стеноз ПОБА, \%, Ме (ИИ) & $30,0(0,00-35,0)$ & $0,00(0,00-33,0)$ & 0,068 \\
\hline Стеноз ЛПБА, \%, Ме (ИИ) & $0,00(0,00-37,0)$ & $0,00(0,00-29,0)$ & 0,065 \\
\hline Стеноз ППБА, \%, Ме (ИИ) & $23,0(0,00-50,0)$ & $0,00(0,00-24,5)$ & 0,0001 \\
\hline Стеноз ЛПкА, \%, Ме (ИИ) & $35,0(0,00-45,0)$ & $0,00(0,00-0,00)$ & 0,0001 \\
\hline Стеноз ППкА, \%, Ме (ИИ) & $0,00(0,00-40,0)$ & $0,00(0,00-0,00)$ & 0,004 \\
\hline Стеноз ЛЗББА, \%, Ме (ИИ) & $0,00(0,00-50,0)$ & $0,00(0,00-0,00)$ & 0,004 \\
\hline Стеноз ПЗББА, \%, Ме (ИИ) & $0,00(0,00-30,0)$ & $0,00(0,00-0,00)$ & 0,004 \\
\hline Стеноз ЛПББА, \%, Ме (ИИ) & $0,00(0,00-70,0)$ & $0,00(0,00-0,00)$ & 0,001 \\
\hline Стеноз ППББА, \%, Ме (ИИ) & $0,00(0,00-70,0)$ & $0,00(0,00-0,00)$ & 0,0001 \\
\hline
\end{tabular}

Примечания: АСБ - атеросклеротическая бляшка; АНК - артерии нижних конечностей; МаксСТСА - максимальный стеноз сонных артерий; ОСА - общая сонная артерия; СуммСтСА - суммарный стеноз сонных артерий; ОБА - общая бедренная артерия; ПБА - поверхностная бедренная артерия; ПкА - подколенная артерия; ЗББА - задняя большеберцовая артерия; ПББА - передняя большеберцовая артерия; Ме - медиана; ИИ интерквартильный интервал

Таблица 3. Данные лабораторных методов исследования

\begin{tabular}{|c|c|c|c|}
\hline Признак & $\begin{array}{c}\text { Группа I } \\
\text { ИБС+СД }(n=67)\end{array}$ & $\begin{array}{c}\text { Группа II } \\
\text { ИБС (n=70) }\end{array}$ & $\mathbf{p}$ \\
\hline ОХС, ммоль/л, Ме (ИИ) & $4,31(3,54-5,57)$ & $5,00(4,08-5,71)$ & 0,054 \\
\hline ХС ЛНП, ммоль/л, Ме (ИИ) & $2,44(1,75-3,60)$ & $2,93(1,98-3,76)$ & 0,144 \\
\hline ХС лВП, ммоль/л, Ме (ИИ) & $1,08(0,92-1,31)$ & $1,27(1,08-1,57)$ & 0,003 \\
\hline ТГ, ммоль/л, Ме (ИИ) & $1,90(1,30-2,54)$ & $1,54(1,11-1,86)$ & 0,007 \\
\hline Гликированный гемоглобин, \%, Ме (ИИ) & $6,50(5,70-7,90)$ & $5,00(4,70-5,30)$ & 0,0001 \\
\hline Креатинин, мкмоль/л, Ме (ИИ) & $104(97-117)$ & $104(93,7-115)$ & 0,546 \\
\hline СКФ, мл/мин/1,73 м², Ме (ИИ) & $58,0(48,7-70,0)$ & $58,5(51,7-68,0)$ & 0,672 \\
\hline ВчСРБ, мг/дл, Ме (ИИ) & $2,72(1,38-6,18)$ & $1,71(0,83-4,37)$ & 0,128 \\
\hline ИЛ-1ß, пг/мл, Ме (ИИ) & $2,04(0,98-2,52)$ & $2,43(1,84-3,19)$ & 0,010 \\
\hline ИЛ-6, пг/мл, Ме (ИИ) & $1,84(0,73-4,41)$ & $3,73(2,27-10,2)$ & 0,008 \\
\hline ИЛ-8, пг/мл, Ме (ИИ) & $15,9(6,50-33,8)$ & $20,8(7,04-63,8)$ & 0,240 \\
\hline ИЛ-10, пг/мл, Ме (ИИ) & $3,90(3,24-4,37)$ & $3,46(2,62-4,49)$ & 0,299 \\
\hline ФНО-а, пг/мл, Ме (ИИ) & $1,45(0,82-2,55)$ & $1,16(0,93-1,45)$ & 0,163 \\
\hline
\end{tabular}

Примечания: вчСРБ - высокочувствительный С-реактивный белок; ИЛ-1 $\beta$ - интерлейкин-1 $\beta$; ИЛ-6 - интерлейкин-6; ИЛ-8 - интерлейкин-8; ИЛ-10 - интерлейкин-10; СКФ - скорость клубочковой фильтрации; ФНО-а - фактор некроза опухоли а; ОХС - общий холестерин; ХС ЛНП холестерин липопротеидов низкой плотности; ХС ЛВП - холестерин липопротеидов высокой плотности; ТГ - триглицериды; Ме - медиана; ИИ интерквартильный интервал 


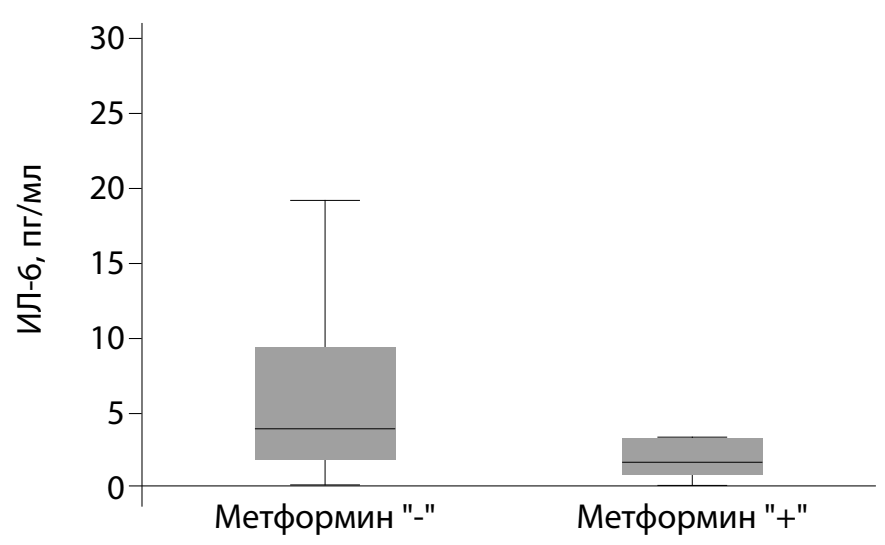

Рис. 1. Содержание интерлейкина-6 у пациентов в зависимости от терапии метформином.

всех стенозов сонных артерий с обеих сторон, а также определяли максимальный процент стеноза у конкретного пациента (МаксСтСА).

\section{Основной исход исследования}

Исследованием не предусмотрена оценка влияния медицинского вмешательства на риск развития неблагоприятных исходов. Цель исследования считалась достигнутой в случае полного обследования пациента в соответствии с протоколом исследования, что делало возможным анализ клинико-лабораторных и инструментальных показателей в подгруппах пациентов.

\section{Анализ в подгруппах}

Пациенты исследуемой когорты были разделены на две группы в зависимости от наличия СД2.

\section{Этическая экспертиза}

Протокол исследования одобрен Этическим комитетом ФГБОУ ВО ЮУГМУ Минздрава России на заседании от 14.01.2017 (выписка из протокола заседания №1).

\section{Статистический анализ}

Размер выборки предварительно не рассчитывался.

Методы статистического анализа данных. Статистический анализ полученных данных проводили на персональном компьютере с использованием программного обеспечения Micrososft Excel и пакета статистического анализа данных IBM SPSS Statistics, версия 22. Качественные переменные описывали абсолютными и относительными частотами (процентами). Количественные переменные описывали следующими статистиками: средним арифметическим значением (М), стандартным отклонением от среднего арифметического значения (SD) в случае нормального распределения показателя, медианой (Ме) с указанием интерквартильного интервала (ИИ) В случае ненормального распределения переменных. Для проверки распределения на предмет соответствия нормальному закону использовали критерий Колмогорова-Смирнова. Для определения взаимного влияния показателей использовали корреляционный анализ Спирмена (для определения взаимосвязи качественных и количественных показателей) и Пирсона (с целью определения взаимного влияния между количественными показателями). Для оценки значимости различий между группами использовали критерий Манна-Уитни.
Различия считали статистически значимыми при уровне ошибки $p<0,05$. При сравнении качественных показателей использовали $\mathrm{X}^{2}$-критерий Пирсона.

\section{РЕЗУЛЬТАТЫ}

\section{Объекты (участники) исследования}

В исследование были включены 137 пациентов (77 мужчин и 60 женщин) с ИБС. Средний возраст пациентов составлял $62,0(57,0-66,0)$ лет. В зависимости от наличия СД2 пациенты были распределены в две группы в 1-ю группу были включены 67 пациентов с ИБС и СД2, во 2-ю - 70 с ИБС. Клиническая характеристика пациентов обеих групп представлена в табл. 1.

Как следует из данных табл. 1, пациенты были сопоставимы по полу и возрасту. В 1-й группе больных были статистически значимо выше средние значения ИМТ и ОТ. В группе пациентов с СД2 средняя длительность ГБ и ИБС была статистически значимо больше в сравнении с больными 2-й группы, что, вероятно, требовало приема нескольких антигипертензивных препаратов, в т.ч. блокаторов медленных кальциевых каналов. В группе пациентов с ИБС и СД2 ХСН была диагностирована у 92,5\% пациентов, в то время как у пациентов с ИБС в отсутствие СД2 - у 57,1\% ( $p=0,0001)$. Вероятно, это объясняет большую частоту назначения диуретиков в 1-й группе. На момент включения в исследование лекарственную терапию СД получали 58 (86,5\%) пациентов. 45 (67,1\%) пациентов получали пероральные сахароснижающие препараты (ПССП), инсулинотерапию получали 25 (37,3\%) больных, ПССП в сочетании с инсулинотерапией принимали 10 (14,9\%) человек. Среди пациентов, получающих ПССП, 31 (46,2\%) человек получал метформин, 26 (38,8\%) - препараты сульфонилмочевины, 16 (23,8\%) - комбинированную терапию ПССП, 3 (4,47\%) пациента получали ингибиторы дипептидилпептидазы-4, 1 (1,49\%) - ингибитор натрий-глюкозного котранспортера 2 типа. Средняя доза метформина составляла 1000 (500-1600) мг.

\section{Основные результаты исследования}

Результаты дуплексного сканирования периферических артерий представлены в табл. 2.

Как следует из данных табл. 2, пациенты с ИБС и СД2 отличались статистически значимо большими значениями стенозирования артерий каротидного бассейна и АНК на всех уровнях. Также в группе пациентов с СД2 значимо чаще визуализировались АСБ в артериях каротидного бассейна, но не в АНК. Интересно отметить, что у больных с СД2 были выявлены статистически значимо большие значения ТКИМ в бедренных артериях в сравнении с пациентами без СД, в то время как значения ТКИМ сонных артерий не различались между группами исследуемых пациентов.

В табл. 3 отражены данные лабораторных методов исследования.

В группе пациентов с СД2 были выявлены статистически значимо меньшие значения ИЛ-1 $\beta$ и ИЛ-6, в то время как содержание других цитокинов не различалось между группами.

Необходимо отметить взаимосвязи маркеров субклинического воспаления и проводимой терапии.

Как следует из рис. 1, пациенты, получающие мет- 
формин, отличались значимо меньшими значениями ИЛ-6 - 1,43 (0,61-3,06) пг/мл против 3,62 (1,71-9,58) пг/мл $(p=0,003)$. Кроме того, доза метформина обратно коррелировала с уровнем ИЛ-6 ( $r=-0,314 ; p=0,003)$. Среди пациентов, которые получали терапию метформином, уровни ИЛ-1 $\beta$ также были значимо меньше в сравнении с пациентами, не получающими метформин - 1,97 (1,13-2,38) пг/мл против 2,28 $(1,40-3,07)$ пг/мл $(p=0,044)$. Однако корреляционные связи между дозой метформина и уровнем ИЛ$1 \beta$ не достигали статистической значимости ( $r=-0,205$; $\mathrm{p}=0,053)$.

\section{Дополнительные результаты исследования}

При изучении взаимосвязи лабораторных показателей субклинического воспаления и ультрасонографических маркеров поражения периферических артерий выявлены слабые корреляционные связи вчСРБ и ТКИМср ОСА $(r=0,205 ; p=0,021)$, степени стенозирования ПБА $(r=0,244 ; p=0,006)$ и ЗББА $(r=0,200 ; p=0,024)$. Выявлены слабые корреляционные связи между уровнем ИЛ-1 $\beta$ и ТКИМ ЛПБА ( $r=0,312 ; p=0,006)$, а также степенью стенозирования ППБА ( $r=0,418 ; p=0,005)$. Уровень ИЛ-6 прямо коррелировал со степенью стенозирования ЗББА $(r=0,327 ; p=0,027)$ и ПБА $(r=0,422 ; p=0,004)$, а также с ТКИМ ЛОСА $(r=0,303 ; p=0,045)$ и ТКИМ ЛПБА $(r=0,410$; $\mathrm{p}=0,006)$. Обнаружены корреляционные связи слабой силы - между ФНО- $а$ и ТКИМ ОБА ( $r=0,345 ; p=0,046)$.

\section{Нежелательные явления}

В ходе исследования не было зарегистрировано нежелательных явлений, связанных с проводимыми диагностическими вмешательствами.

\section{ОБСУЖДЕНИЕ}

\section{Резюме основного результата исследования}

В проведенном нами исследовании пациенты с СД2 отличались статистически значимо меньшими значениями ИЛ-1 $\beta$ и ИЛ-6, а также большей тяжестью атеросклероза периферических артерий. При этом были выявлены прямые корреляционные взаимосвязи уровней провоспалительных цитокинов и ультрасонографических маркеров тяжести атеросклероза, что находится в соответствии с ранее опубликованными работами $[14,15]$.

\section{Обсуждение основного результата исследования}

В течение длительного времени дискутируется роль воспаления в атерогенезе [16]. Анализ различных экспериментальных и клинических исследований позволил целому ряду авторов рассматривать воспаление как «свидетеля» комплекса реакций в инициации и прогрессировании атеросклероза, не играющего значимой роли в патогенезе атеросклероза и связанных с ним сердечно-сосудистых заболеваний. В данном контексте показатели интенсивности воспаления рассматривались лишь как возможные маркеры, отражающие распространенность и тяжесть атеросклеротического поражения, определение которых не может существенным образом модифицировать терапию [17, 18]. Однако в 2017 г. были опубликованы результаты многоцентрового рандомизированного клинического исследования CANTOS (Canakinumab Antiinflammatory Thrombosis Outcome Study), в котором изучалось влияние терапевтического человеческого моноклонального антитела к ИЛ-1 $\beta$ канакинумаба на развитие неблагоприятных сердечно-сосудистых событий у пациентов, перенесших инфаркт миокарда и имеющих повышенные значения вчСРБ. Терапия канакинумабом в дозе 150 мг в течение в среднем 3,7 лет наблюдения приводила к снижению относительного риска нефатального инфаркта миокарда, нефатального инсульта или кардиоваскулярной смерти на 15\% (относительный риск 0,85; 95\% доверительный интервал 0,74-0,98; $\mathrm{p}=0,021$ ) [19]. Таким образом, впервые была доказана возможность снижения сердечно-сосудистых рисков с помощью препаратов, влияющих на воспаление, что, в свою очередь, является подтверждением «воспалительной гипотезы» атеротромбоза.

В свете результатов данного исследования изучение воспаления у пациентов с кардиоваскулярными заболеваниями, в том числе в сочетании с СД2, приобретает особую важность и в ближайшем будущем будет способствовать индивидуализации терапии и дальнейшему снижению резидуального риска сердечно-сосудистых осложнений.

В целом ряде клинических исследований было установлено увеличение содержания провоспалительных цитокинов у пациентов с СД2, в том числе в сочетании с атеросклеротическими кардиоваскулярными заболеваниями [20, 21].

Анализ факторов, которые, по нашему мнению, могли объяснять полученные в проведенном исследовании различия в уровнях ИЛ-1 $\beta$ и ИЛ-6, позволил установить, что уровни ИЛ-6 обратно коррелировали с дозой метформина. Полученные нами результаты согласуются с данными ряда исследований из различных областей клинической и экспериментальной медицины, в которых изучались плейотропные эффекты метформина [22]. Влияние терапии метформином на уровень ИЛ-6 особенно активно изучается в популяции лиц женского пола с синдромом поликистозных яичников. Так, в систематическом обзоре Xinghua Хu и соавт. было установлено, что в целом ряде клинических исследований терапия метформином у женщин с синдромом поликистозных яичников приводила к статистически значимому снижению ИЛ-6 [23]. При этом снижение ИЛ-6 тесно коррелировало со снижением инсулинорезистентности [24]. В исследовании 3.А. Шаенко и соавт. терапия метформином в дозе 1500-2500 мг в сутки в сочетании с пиоглитазоном у пациентов с ИБС и СД2 в течение 6 мес приводила к статистически значимому снижению уровней ФНО-а и ИЛ-6. При этом уровень ИЛ-6 снизился почти в 4 раза в сравнении с исходными значениями [25]. В работе W. Chen и соавт. у пациентов с СД2 метформин в дозе 1000-1500 мг в сутки приводил к снижению уровней ИЛ-6 в моче и плазме крови [26]. В крупное мультицентровое исследование BARI 2D было включено 2368 больных ИБС и СД2 [27]. Среди пациентов, рандомизированных в группу лечения метформином и/ или тиазолидиндионом, в течение пятилетнего периода наблюдения отмечались статистически значимо более низкие значения СРБ, фибриногена и ингибитора активатора плазминогена-1 в сравнении с пациентами, получающими препараты сульфонилмочевины или меглитиниды. 
На сегодняшний день активно изучаются механизмы противовоспалительного действия метформина. В исследовании A.R. Cameron и соавт. было установлено, что противовоспалительные эффекты метформина реализуются также в популяции лиц с нормальным углеводным обменом [28]. Метформин (в опыте с гепатоцитами животных) подавлял ФНО-а-индуцированную деградацию негативного регулятора NF-KB IкB, результатом чего являлось ингибирование экспрессии CINC-1/CXCL1, CXCL2, IL-1 $\beta$ и IL-6. Метформин также подавлял секрецию провоспалительных цитокинов макрофагами. В экспериментальных исследованиях было выявлено ингибирование NF-кB также путем активации АМФ-активируемой протеинкиназы (AMP activated protein kinase, AMPK) [29]. Еще одним возможным механизмом противовоспалительного действия метформина является ингибирование образования конечных продуктов гликирования, которые, в свою очередь, оказывают провоспалительные эффекты. Важным является тот факт, что противовоспалительные эффекты метформина показаны на различных типах клеток - гладкомышечные клетки, эндотелиоцитах, гепатоцитах [30].

\section{Ограничения исследования}

Ограничением исследования является его дизайн, поскольку предпочтительным в данном случае было бы проведение рандомизированного слепого исследования с определением маркеров низкоинтенсивного воспаления до начала приема метформина/плацебо и в процессе терапии, а также по ее окончании.

\section{ЗАКЛЮЧЕНИЕ}

В проведенном исследовании пациенты с ИБС и СД2 В сравнении с пациентами без нарушений углеводного обмена отличались статистически значимо большими значениями стенозирования периферических артерий. При этом уровни циркулирующих маркеров воспаления прямо коррелировали с ультрасонографическими показателями тяжести атеросклеротического поражения периферических артерий, что согласуется с результатами ранее проведенных работ [13, 14]. Уровни циркулирующих ИЛ-1 $\beta$ и ИЛ-6 в группе пациентов с ИБС и СД2 были статистически значимо ниже в сравнении с пациентами без СД. Доза получаемого метформина обратно коррелировала с уровнем ИЛ-6. В контексте изучения противовоспалительных эффектов метформина в клинических и экспериментальных исследованиях полученные нами результаты, возможно, являются еще одним свидетельством плейотропных эффектов метформина в условиях реальной клинической практики у пациентов с ИБС, СД2 и атеросклерозом периферических артерий. Противовоспалительное действие метформина рассматривается как один из механизмов, обеспечивающих кардиопротективное влияние данного препарата [31]. Необходимы дальнейшие исследования для успешной трансляции этих данных в различные отрасли клинической медицины.

\section{ДОПОЛНИТЕЛЬНАЯ ИНФОРМАЦИЯ}

Источник финансирования. Финансирование осуществлялось в рамках научно-исследовательской программы ФГБОУ ВО ЮУГМУ Минздрава России, Челябинск.

Конфликт интересов. Авторы декларируют отсутствие явных и потенциальных конфликтов интересов, связанных с публикацией настоящей статьи.

Участие авторов. Генкель В.В. - концепция, сбор материалов, анализ результатов, написание текста статьи; Никушкина К.В. - сбор материалов, анализ результатов, написание текста статьи; Никонова Т.И. - сбор материалов, анализ результатов, написание текста статьи; Шапошник И.И. - концепция, дизайн работы, анализ результатов, написание текста статьи.

\section{СПИСОК ЛИТЕРАТУРЫ | REFERENCES}

1. Ross R. Atherosclerosis - an inflammatory disease. N Engl J Med. 1999;340(2):115-126. doi: 10.1056/NEJM199901143400207

2. Ammirati E, Moroni F, Norata GD, et al. Markers of inflammation associated with plaque progression and instability in patients with carotid atherosclerosis. Mediators Inflamm. 2015;2015:718329. doi: 10.1155/2015/718329

3. Soeki T, Sata M. Inflammatory Biomarkers and Atherosclerosis. Int Heart J. 2016;57(2):134-139. doi: 10.1536/ihj.15-346

4. Boehme AK, McClure LA, Zhang Y, et al. Inflammatory Markers and Outcomes After Lacunar Stroke: Levels of Inflammatory Markers in Treatment of Stroke Study. Stroke. 2016;47(3):659-667. doi: 10.1161/STROKEAHA.115.012166

5. Беленькова Ю.А., Кашталап В.В., Каретникова В.Н., и др. Факторы воспаления, влияющие на прогноз у больных инфарктом миокарда с подъемом сегмента ST, подвергшихся чрескожным коронарным вмешательствам // Международный журнал интервениионной кардиоангиологии. - 2012. - №29. - С. 51-58. [Belenkova YA, Kashtalap VV, Karetnikova VN, et al. Inflammatory factors affecting prognosis in patients with myocardial infarction with ST-segment elevation undergoing percutaneous coronary interventions. International Journal of Interventional Cardioangiology. 2012;(29):51-58. (In Russ.)]

6. Xiong XD, Xiong WD, Xiong SS, et al. Research Progress on the Risk Factors and Outcomes of Human Carotid Atherosclerotic Plaques. Chin Med J (Engl). 2017;130(6):722-729. doi: 10.4103/0366-6999.201598
7. Hameed I, Masoodi SR, Mir SA, et al. Type 2 diabetes mellitus: From a metabolic disorder to an inflammatory condition. World J Diabetes. 2015;6(4):598-612. doi: 10.4239/wjd.v6.i4.598

8. Климонтов В.В., Тян Н.В., Фазуллина О.Н., и др. Клинические и метаболические факторы, ассоциированные с хроническим воспалением низкой интенсивности, у больных сахарным диабетом 2 типа // Сахарный диабет. - 2016. -Т. 19. - №4. C. 295-302. [Klimontov VV, Tyan NV, Fazullina ON, et al. Clinical and metabolic factors associated with chronic low-grade inflammation in type 2 diabetic patients. Diabetes Mellitus. 2016;19(4):295-302. (In Russ.)] doi: 10.14341/dm7928

9. Wang Z, Shen XH, Feng WM, et al. Analysis of Inflammatory Mediators in Prediabetes and Newly Diagnosed Type 2 Diabetes Patients. $J$ Diabetes Res. 2016;2016:7965317. doi: 10.1155/2016/7965317

10. Yamamoto Y, Yamamoto H. RAGE-Mediated Inflammation, Type 2 Diabetes, and Diabetic Vascular Complication. Front Endocrinol (Lausanne). 2013;21(4):105. doi: 10.3389/fendo.2013.00105

11. Freitas Lima LC, Braga VA, do Socorro de Franca Silva M, et al. Adipokines, diabetes and atherosclerosis: an inflammatory association. Front Physiol. 2015;6:304. doi: 10.3389/fphys.2015.00304

12. Puz P, Lasek-Bal A, Ziaja D, et al. Inflammatory markers in patients with internal carotid artery stenosis. Arch Med Sci. 2013;9:254-260. doi: 10.5114/aoms.2013.34533

13. Zhang $B$, Wang J, Xu Y, et al. Correlative association of interleukin-6 with intima media thickness: a meta-analysis. Int I Clin Exp Med. 2015;8(3):4731-4743. 
14. Signorelli SS, Fiore V, Malaponte G. Inflammation and peripheral arterial disease: the value of circulating biomarkers (Review). Int J Mol Med. 2014:33(4):777-783. doi: 10.3892/ijmm.2014.1657

15. Hazarika S, Annex BH. Biomarkers and Genetics in Peripheral Artery Disease. Clin Chem. 2017;63(1):236-244. doi: $10.1373 /$ clinchem.2016.263798

16. Libby P, Hansson GK. Inflammation and Immunity in Diseases of the Arterial Tree: Players and Layers. Circ Res. 2015;116(2):307-311. doi: 10.1161/CIRCRESAHA.116.301313

17. Nordestgaard BG, Zacho J. Lipids, atherosclerosis and CVD risk: is CRP an innocent bystander? Nutr Metab Cardiovasc Dis. 2009;19(8):521-524. doi: 10.1016/j.numecd.2009.07.005

18. Lin GM, Chu KM, Han CL. Reverse epidemiology reflects C-reactive protein as a bystander of atherosclerosis in established systemic inflammation models. Int J Cardiol. 2011;146(3):422-423. doi: 10.1016/j.ijcard.2010.10.094

19. Ridker PM, Everett BM, Thuren T, et al. Antiinflammatory Therapy with Canakinumab for Atherosclerotic Disease. N Engl J Med. 2017;377(12):1119-1131. doi: 10.1056/NEJMoa1707914

20. Бардымова Т.П., Протасов К.В., Цыреторова С.С., и др. Сахарный диабет 2-го типа и ишемическая болезнь сердца // Acta Biomedica Scientifica. - 2017. - T. 2. - №1. - C. 100-106. [Bardymova TP, Protasov KV, Tsyretorova SS, et al. Type 2 diabetes mellitus and coronary heart disease. Acta Biomedica Scientifica. 2017:2(1):100-106. (In Russ.)]

21. Петелина Т.И., Мусихина Н.А., Гапон Л.И., и соавт. Сравнительная характеристика параметров липидного спектра и маркеров сосудистого воспаления в группах пациентов со стабильной стенокардией при наличии и отсутствии сахарного диабета 2 типа // Сахарный диабет. - 2017. - Т. 20. - №3. - C. 194-200. [Petelina TI, Musikhina NA, Gapon LI, et al. Lipid profile and markers of vascular inflammation in patients with stable angina in the presence and absence of type 2 diabetes mellitus. Diabetes Mellitus. 2017:20(3):194-200. (In Russ.)] doi: 10.14341/7959

22. Руяткина Л.А., Руяткин Д.С. Многоплановые эффекты метформина у пациентов с сахарным диабетом 2 типа // Сахарнылй duaбem. - 2017. - T. 20. - №3. - C. 210-219. [Ruyatkina LA, Ruyatkin DS. Multidimensional effects of metformin in patients with type 2 diabetes. Diabetes Mellitus. 2017;20(3):210-219. (In Russ.)]. doi: 10.14341/dm2003458-64

23. Xu X, Du C, Zheng $\mathrm{Q}$, et al. Effect of metformin on serum interleukin-6 levels in polycystic ovary syndrome: a systematic review. BMC Womens Health. 2014;14:93. doi: 10.1186/1472-6874-14-93

24. Ciaraldi TP, Aroda V, Mudaliar SR, et al. Inflammatory cytokines and chemokines, skeletal muscle and polycystic ovary syndrome: Effects of pioglitazone and metformin treatment. Metabolism 2013:62:1587-1596. doi: 10.1016/j.metabol.2013.07.004

25. Шаенко 3.А., Расин М.С. Эффективность и безопасность метформина и пиоглитазона у пациентов с ишемической болезнью сердца и сахарным диабетом 2-го типа // Международный эндокринологический журнал. - 2015. - №2. - C. 66-70. [Shaenko ZA, Rasin MS. Efficiency and Safety of Metformine and Pioglitazone in Patients with Coronary Heart Disease and Diabetes Mellitus Type 2. International Journal of Endocrinology. 2015;(2):66-70. (In Russ.)]

26. Chen W, Liu X, Ye S. Effects of metformin on blood and urine pro-inflammatory mediators in patients with type 2 diabetes. J Inflamm (Lond). 2016;24(13):34. doi: 10.1186/s12950-016-0142-3

27. Sobel BE, Hardison RM, Genuth S, et al. BARI 2D Investigators. Profibrinolytic, anti-thrombotic, and antiinflammatory effects of an insulin-sensitizing strategy in patients in the Bypass Angioplasty Revascularization Investigation 2 Diabetes (BARI 2D) trial. Circulation. 2011:124:695-703. doi: 10.1161/CIRCULATIONAHA.110.014860

28. Cameron AR, Morrison VL, Levin D, et al. Anti-Inflammatory Effects of Metformin Irrespective of Diabetes Status. Circ Res. 2016;119(5):652665. doi: 10.1161/CIRCRESAHA.116.308445

29. Saisho Y. Metformin and Inflammation: Its Potential Beyond Glucose-lowering Effect. Endocr Metab Immune Disord Drug Targets. 2015;15(3):196-205. doi: 10.2174/1871530315666150316124019

30. Hattori Y, Hattori K, Hayashi T. Pleiotropic benefits of metformin: macrophage targeting its anti-inflammatory mechanisms. Diabetes. 2015:64(6):1907-1909. doi: 10.2337/db15-0090

31. Nesti L, Natali A. Metformin effects on the heart and the cardiovascular system: A review of experimental and clinical data. Nutr Metab Cardiovasc Dis. 2017;27(8):657-669. doi: 10.1016/j.numecd.2017.04.009

\section{ИНФОРМАЦИЯ ОБ АВТОРАХ [AUTHORS INFO]}

*Генкель Вадим Викторович [Vadim V. Genkel]; адрес: Россия, 454092, Челябинск, ул. Воровского, д. 64 [address: 64 Vorovskogo street, 454092 Chelyabinsk, Russian Federation]; ORCID: http://orcid.org/0000-0001-5902-3803; eLibrary SPIN: 2519-6100; e-mail: henkel-07@mail.ru

Никушкина Карина Викторовна, к.м.н. [Karina V. Nikushkina, MD, PhD]; ORCID: http://orcid.org/0000-0002-3900-9278; eLibrary SPIN: 4216-6139; e-mail: knikushkina81@gmail.com

Никонова Танзиля Ильдаровна [Tansilla I. Nikonova]; ORCID: http://orcid.org/0000-0001-9595-4664; eLibrary SPIN: 4331-1458; e-mail: nikonova_19750225@mail.ru

Шапошник Игорь Иосифович, д.м.н., професcop [lgor I. Shaposhnik, MD, PhD, Professor]; ORCID: http://orcid.org/0000-0002-7731-7730; eLibrary SPIN: 3184-5994; e-mail: shaposhnik@yandex.ru

\section{ЦИТИРОВАТЬ:}

Генкель В.В., Никушкина К.В., Никонова Т.И., Шапошник И.И. Атеросклероз периферических артерий и показатели низкоинтенсивного воспаления у пациентов с ишемической болезнью сердца и сахарным диабетом 2 типа // Сахарный диабет. — 2018. - Т. 21. — №3. — С. 178-185. doi: 10.14341/DM9392

\section{TO CITE THIS ARTICLE:}

Genkel VV, Nikushkina KV, Nikonova TI, Shaposhnik II. Peripheral arterial disease and indicators of low-grade inflammation in patients with coronary artery disease and type 2 diabetes mellitus. Diabetes Mellitus. 2018;21(3):178-185. doi: 10.14341/DM9392 